\title{
A Tecnologia Digital e o Ciclo Investigativo na Formação Docente sobre Conceitos Estatísticos
}

\author{
Elvis Melo ${ }^{1}$, Carmélia Xavier $^{1}$, Clésia Nunes $^{1}$, Rodolfo Carvalho $^{2}$, Flávia Viana ${ }^{2}$, \\ Dennys Maia ${ }^{1}$
}

${ }^{1}$ Instituto Metrópole Digital - Universidade Federal do Rio Grande do Norte (UFRN) Av. Sen. Salgado Filho, 3000 - Lagoa Nova, CEP: 59.078-970 - Natal - RN - Brasil

\author{
${ }^{2}$ Centro de Educação - UFRN
}

\{elvismedeiros.mm, carmeliaxavierxavier, rodolfoac, flaviaviana.ufrn\}@gma il.com, clesia_ja@hotmail.com, dennys@imd.ufrn.br

\begin{abstract}
The teaching of Statistics is related to a data production context and an investigative cycle. With the help of digital technologies, these processes are facilitated, but require teacher appropriation. This paper aims to analyze a sequence of teaching based on the investigative cycle that sought to integrate digital technologies during their execution in a formative process for professional development for teachers who teach mathematics. Among the results, the teachers consider significant the integration of technologies in the construction and application of teaching sequences.

Resumo. $O$ ensino de Estatística está relacionado a um contexto de produção de dados e a um ciclo investigativo. Com a ajuda das tecnologias digitais, esses processos são facilitados, mas demandam apropriação dos docentes. Este artigo tem o objetivo de analisar uma sequência de ensino baseada no ciclo investigativo que buscou integrar tecnologias digitais durante sua execução em processo formativo para o desenvolvimento profissional para professores que ensinam Matemática. Dentre os resultados, os docentes julgam significativa a integração das tecnologias na construção e aplicação de sequências de ensino.
\end{abstract}

\section{Introdução}

Habilidades ligadas ao pensamento estatístico no Ensino Fundamental da Educação Básica têm contribuição significativa no tratamento da informação para $o$ desenvolvimento do pensamento científico [Cazorla e Santana, 2010]. Essa abordagem encontra amparo na chamada Educação Matemática Crítica [Skovsmose, 2008] que vê a Matemática como uma ferramenta para formar os estudantes com vistas à equidade na aprendizagem. Visão também alinhada ao que propõe a Base Nacional Comum Curricular (BNCC) ao destacar, na unidade temática de Estatística e Probabilidade, a abordagem de conceitos presentes em muitas situações-problema da vida cotidiana [Brasil, 2017].

Dessa forma, as práticas sociais com o Tratamento da Informação podem ser proporcionadas por diversos meios tecnológicos. De acordo com Castro e Castro-Filho (2012) as tecnologias digitais contribuem para a promoção do pensamento estatístico, pois ampliam os procedimentos e estratégias de coleta, organização de dados, além do desenvolvimento do senso crítico, a autonomia, a criatividade e a leitura.

Neste sentido, o objetivo deste trabalho é analisar uma sequência de ensino baseada no ciclo investigativo que buscou integrar tecnologias digitais durante sua execução. A experiência foi realizada no contexto de um grupo colaborativo com professores dos anos finais de uma escola pública do município do Natal/RN. Este trabalho foi realizado no âmbito do projeto Desenvolvimento Profissional de Professores que Ensinam Matemática (D-Estat) que trabalha conceitos estatísticos. 
VIII Congresso Brasileiro de Informática na Educação (CBIE 2019)

Anais do XXV Workshop de Informática na Escola (WIE 2019)

\section{Tecnologias Digitais na Formação Docente em Estatística}

O estudo de gráficos com auxílio do ambiente computacional contribui para aprendizagem de conceitos estatísticos. As tecnologias digitais, na maioria das vezes, auxiliam na exploração de um conjunto de atividades, propiciando novas formas de pensar e agir matematicamente [Castro e Castro-Filho, 2012]. Porém, é fundamental que o professor conheça as possibilidades das tecnologias digitais para poder integrá-as em sua prática, o que demanda formação para o uso pedagógico dessas tecnologias e tempo para planejar atividades curriculares inovadoras.

É neste sentido que as formações desenvolvidas pela Equipe OBAMA (Objetos de Aprendizagem para Matemática) acontecem no D-Estat, com encontros entre pesquisadores e professores colaboradores, no horário de planejamento do professor, integrando tecnologias digitais, para a promoção do desenvolvimento profissional.

Do ponto de vista didático, o uso das novas tecnologias propicia trabalhar em sala de aula com investigação e experimentação na Matemática, considerando que permite ao aprendiz vivenciar experiências, fomentar e construir o próprio conhecimento. O aluno participa da ação educativa a partir da interação com os métodos e meios para organizar a própria experiência. A participação do professor como facilitador dos processos ensino e aprendizagem é relevante para permitir que o aluno desenvolva habilidades.

O trabalho com Estatística ligado à dinâmica investigativa é importante, pois possibilita ao aluno questionar e procurar relações quando têm que resolver problemas no mundo real [Carvalho, 2001]. Esta concepção está alinhada aos cinco elementos cognitivos propostos por Gal (2002) acerca do letramento estatístico, quais sejam: $(i)$ envolvimento de leitura de textos, gráficos, tabelas; (ii) conhecimentos estatísticos; (iii) conhecimentos matemáticos; (iv) conhecimentos do contexto e (v) capacidade de elaboração de questões críticas.

Para o desenvolvimento deste letramento, Wild e Pfannkuch (1999) investigam os processos complexos do pensamento envolvidos na resolução de problemas da realidade, compreendendo a Estatística como possibilidade real para obter uma melhoria nas soluções desses problemas. Para suas investigações, propuseram o modelo PPDAC (Problema, Planejamento, Dados, Análise e Conclusões) que visa resolver um problema real, geralmente com a intenção de mudar um sistema para melhorar um processo.

No modelo PPDAC para o ciclo investigativo, o (i) Problema diz respeito ao conhecimento do contexto dos dados e a definição do problema a ser investigado; (ii) Planejamento inclui a definição das ações para a investigação, como o sistema de medição, o projeto de amostragem, a gestão dos dados e planos de experimentação e análise por meio da categorização das variáveis; (iii) Dados, incluem o processo de coleta de dados e sua organização; (iv) Análise é realizado o tratamento e análise dos dados, aplicação de técnicas e também a geração de hipóteses; e $(v)$ Conclusão encerra a investigação com um posicionamento crítico, reflexivo, com a comunicação dos dados e geração de novas ideias, novos questionamentos.

Segundo Cazorla e Santana (2010), uma sequência de ensino são atividades em que o professor conduz todas as etapas propostas em conjunto com os alunos. As sequências de ensino elaboradas no âmbito do D-Estat têm o objetivo de promover o desenvolvimento do pensamento estatístico, tornando o sujeito ativo na sua aprendizagem, ressignificando os seus conhecimentos prévios sobre sua realidade.

\section{Procedimentos, Métodos e Técnicas da Pesquisa}

O processo formativo na escola iniciou em Maio de 2018, a partir do contato com a gestão e apresentação da proposta do projeto D-Estat. Inicialmente foram aplicados instrumentos diagnósticos para identificar as necessidades formativas de professores 
VIII Congresso Brasileiro de Informática na Educação (CBIE 2019)

Anais do XXV Workshop de Informática na Escola (WIE 2019)

acerca de procedimentos pedagógicos, tecnológicos e do conteúdo estatístico. Com as demandas levantadas, organizamos um encontro para estudarmos, junto com os professores, conceitos estatísticos e o ciclo investigativo do PPDAC. Os encontros ocorreram conforme as fases do PPDAC, no qual foram delimitados procedimentos inerentes ao desenvolvimento das fases com a utilização de tecnologias digitais.

Para promover familiaridade dos professores com as tecnologias digitais e ampliar o espaço formativo, adotamos o Google Classroom (Figura 1) para o compartilhamento de textos e materiais da pesquisa e interações por meio de fóruns e um grupo de WhatsApp (Figura 2) [Maia e Castro-Filho, 2017].

Figura 1. Google Classroom do D-ESTAT

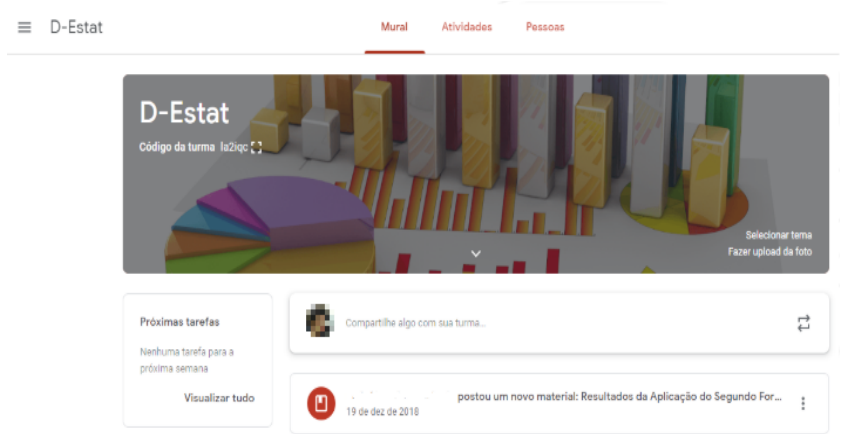

Figura 2. Grupo do WhatsApp dos professores da escola

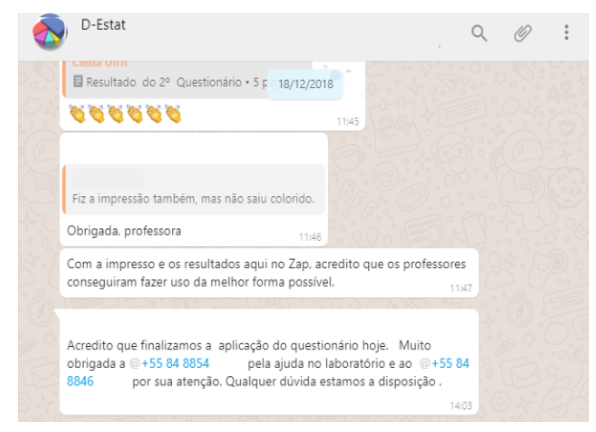

Para a definição do problema, professores e pesquisadores conversaram sobre temas correntes na escola e decidiram realizar um levantamento prévio sobre a percepção dos estudantes sobre as problemáticas da escola. Para tanto, elaborou-se um questionário no Google Formulários com perguntas sobre pontos positivos e negativos que os estudantes observam na escola. Os professores pediram para os estudantes responderem no laboratório de informática durante as suas aulas. Nesse momento, houve colaboração de todos os docentes da escola. Ao analisar os dados das respostas do questionário, a temática mais aparente no formulário foram os altos índices de Violência na escola.

Com as primeiras etapas do PPDAC definidas, o grupo colaborativo passou a elaborar o plano de aula acerca da sequência de ensino a ser desenvolvida. Para tanto, utilizaram a função Plano de Aula disponibilizada pela Plataforma OBAMA [Oliveira et $a l, 2018]$. Dentre as ações definidas foi a produção, junto com os alunos, de um novo formulário para identificação das principais formas de violência sofridas pelos alunos.

$\mathrm{Na}$ fase dos Dados, estudamos os conteúdos estatísticos (ex. medidas de tendência central e tipos de variáveis) com os dados recolhidos no questionário do Google Formulários. No momento de estudo dos temas relacionados à violência, os professores identificaram outros tipos de violência que eram desconhecidos, como por exemplo, a violência simbólica. Para compartilhar esses conhecimentos adquiridos na formação, os professores realizaram uma palestra sobre violência para toda a escola.

Para a etapa de Análise, o grupo colaborativo decidiu que os pesquisadores acompanhariam a execução de uma aula. Assim, no dia 21 de dezembro, uma aula do $6^{\circ}$ ano, explorou-se, a partir dos dados coletados, conteúdos relacionados às medidas de tendência central, assim como a construção de gráficos de barras.

A fase da Conclusão só pode ser efetivada no início do ano letivo seguinte. Como apenas os professores participaram, discutimos sobre quais conclusões os alunos tiveram e avaliamos a experiência com vistas a ressignificá-la em 2019. Os resultados e discussões acerca de tecnologias digitais no ciclo investigativo com vistas à formação docente são apresentados na próxima seção. 
VIII Congresso Brasileiro de Informática na Educação (CBIE 2019)

Anais do XXV Workshop de Informática na Escola (WIE 2019)

\section{Resultados e Discussões}

A primeira etapa de integração de tecnologias digitais no desenvolvimento do PPDAC foi o formulário sobre os pontos positivos e negativos da escola. $\mathrm{O}$ questionário do Google Formulário foi criado de forma colaborativa pelos professores e, em seguida, os alunos foram levados ao laboratório de informática da escola para responderem. Escola e pesquisadores se envolveram para garantir a participação de todos.

O fato de contar com um formulário on-line, acessível por meio de um espaço na própria escola - laboratório de informática - favoreceu a coleta dos dados e também o alto índice de respondentes. A colaboração com outros professores, de outras disciplinas, oportunizou maior engajamento dos alunos que ficaram interessados em contribuir com a pesquisa, a partir de seus pontos de vista.

No encontro realizado sobre os dados coletados pelo formulário, observamos que a violência foi uma das respostas que mais apareceram, porém, sem clareza das diversas formas que a mesma pode se apresentar. Por essa razão os docentes fizeram uma exposição sobre as várias formas de violência para depois aplicar o novo formulário, novamente com o Google Formulário, com os alunos.

Após os estudos sobre os tipos de violência, através de materiais compartilhados no ambiente do Google Classroom e do WhatsApp, os professores identificaram cinco tipos de violência: física, sexual, doméstica, verbal e simbólica. Esta última foi uma surpresa, pois não tinham atentado para esse tipo de violência ao ler as respostas dos alunos (Gráfico 1).

\section{Gráfico 1. Violência sofrida pelos estudantes da escola}

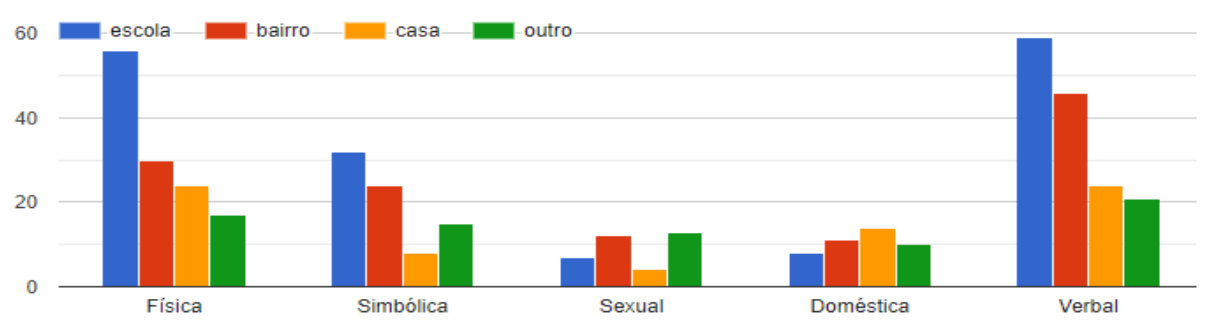

O gráfico 1 foi produzido com suporte do Google Formulários. O gráfico auxiliou nas análises pelos estudantes, promovendo reflexão e criticidade acerca do meio em que vivem. Os dados mostraram que na escola são praticados todos os tipos de violência e serviu para problematizar os tipos de violência que acontecem com maior frequência no âmbito escolar.

Com a coleta de dados do segundo questionário, fizemos a análise dos mesmos e elaboração da sequência de ensino de forma colaborativa, explorando conceitos estatísticos e fazendo uso da Plataforma OBAMA, utilizando o tema problematizador do ciclo investigativo. Os professores também fizeram suas contribuições em casa, assincronamente. Concluída a elaboração do plano de aula, acompanhamos a aplicação da sequência de ensino em uma turma de $6^{\circ}$ ano que proporcionou a observação das estratégias utilizadas pelos alunos para resolver as questões propostas.

$\mathrm{Na}$ etapa final do ciclo investigativo em 2018, avaliamos e concluímos de forma positiva a execução de todo o processo, ficando evidente a relevância da continuidade da pesquisa na escola, realizando os devidos ajustes quanto aos recursos tecnológicos utilizados, como por exemplo, a utilização do Google Classroom que não teve tanto acesso como esperávamos, durante a realização da pesquisa.

\section{Considerações}

Os professores, ao serem convocados a avaliarem o processo formativo, avaliaram 
VIII Congresso Brasileiro de Informática na Educação (CBIE 2019)

Anais do XXV Workshop de Informática na Escola (WIE 2019)

como positivo a integração das tecnologias em todo o processo formativo percorrendo o ciclo investigativo. Porém, relataram que o engajamento fora do período da oficina era pouco, e que seria interessante que fizéssemos tudo no horário da oficina. Alegaram que o Google Formulários ajudou a agilizar e otimizar o tempo e os dados, ampliando seus usos.

Assim como nos artigos analisados, na escola onde a pesquisa está sendo realizada, o que mais contribui para o pouco ou nenhum uso dos dispositivos móveis em sala de aula, se dá pela falta de conhecimento desses dispositivos, ou da ausência de consciência da contribuição positiva que os mesmos podem trazer para a prática pedagógica e a aprendizagem dos alunos.

No ano de 2019, retomamos a projeto D-ESTAT na escola desde o mês de maio e já conseguimos inserir novos recursos tecnológicos que serão utilizados na formação colaborativa. A integração destes nas sequências de ensino com o ciclo investigativo é objeto de estudo de duas dissertações de mestrado da Equipe OBAMA.

\section{Referências}

Brasil (2017). Base Nacional Comum Curricular (BNCC). Disponível em: $<$ http://basenacionalcomum.mec.gov.br>. Acesso em: 09 fev. 2019.

Carvalho, C. (2001). "Interacção entre pares: contributos para a promoção do desenvolvimento lógico e do desempenho estatístico no $7 .^{\circ}$ ano de escolaridade". Tese de Doutorado em Educação - Universidade de Lisboa, Lisboa, 2001.

Castro, J.; Castro-filho, J. A. (2012). "Projeto Um Mundo de Informações: integração de tecnologias digitais ao currículo escolar". In: Anais dos Workshops do CBIE 2012. Porto Alegre: Sociedade Brasileira de Computação, v. 1., 2012, p. 1-10.

Cazorla, I. M.; Santana, E. (2010). "Do tratamento da informação ao letramento estatístico". Itabuna: Via Litterarum.

Gal, I. (2002). "Adult statistical literacy: meaning, components, responsibilities". International Statistical Review, v. 1, n. 70, p. 1-25.

Maia, D. L.; Castro Filho, J. A. (2017). "E quando Skype, Facebook e Whatsapp são usados em formação de professoras que ensinam Matemática?”. Revista Tecnologias na Educação (TecEdu), v. 20, p. 1-20.

Oliveira, A.; Batista, S.; Nascimento, I.; Azevedo, D.; Lima, R.; Oliveira, N.; Maia, D. (2018). "Processo de desenvolvimento de uma ferramenta para elaboração de Planos de Aula de forma colaborativa". In: Anais do III Ctrl+E 2018. Fortaleza.

Skovsmose, O. (2008). “Desafios da Educação Matemática Crítica”. São Paulo: Papirus.

Wild, C.; Pfannkuch, M. (1999). "Statistical Thinking in Empirical Enquiry". International Statistical Review, v.67, n.3, p.223-265, 1999. 